Proceedings

\title{
Asymmetric Iodoetherification of Isosorbide-Derived Glycals: A Regio- and Stereoselective Access to a Variety of $\mathrm{O}$-Substituted Isosorbide Derivatives ${ }^{\dagger}$
}

\author{
Christophe Berini ${ }^{1}$, Aurélie Lavergne ${ }^{2}$, Valérie Molinier ${ }^{3}$, Stéphane Lebrun ${ }^{2}$, \\ Jean-Marie Aubry ${ }^{2}$ and Eric Deniau ${ }^{2, *}$ \\ 1 ORIL Industrie, 13 rue Auguste Desgenetais, 76200 Bolbec, France; chberini@yahoo.fr \\ 2 University Lille, CNRS, Centrale Lille, ENSCL, University Artois, UMR 8181-UCCS-Unité de Catalyse et \\ Chimie du Solide, F-59000 Lille, France; aurelie.lavergne@hotmail.fr (A.L.); \\ stephane.lebrun@univ-lille.fr (S.L.); jean-marie.aubry@univ-lille1.fr (J.-M.A.) \\ 3 Total Exploration Production, Pôle d'Etudes et de Recherche de Lacq, B.P. 47, 64170 Lacq, France; \\ valerie.molinier@total.com \\ * Correspondence: Eric.Deniau@univ-lille.fr \\ + Presented at the 23rd International Electronic Conference on Synthetic Organic Chemistry, 15 November- \\ 15 December 2019; Available online: https://ecsoc-23.sciforum.net/.
}

Published: 14 November 2019

\begin{abstract}
Isosorbide is a competitive starting material for various valuable derivatives by functionalization and/or substitution since it is a renewable and carbon neutral material that is produced on an industrial scale from sorbitol. A set of $O$-alkyl- or $O$-arylated beta-iodo ethers has been synthesized from isosorbide. The key step was the iodoetherification of isosorbide-derived glycals with a variety of oxygenated nucleophiles in the presence of $\mathrm{N}$-iodosuccinimide. trans-Iodo ethers and acetate were obtained in good yields and the removal of iodide affords isosorbide derivatives. The usefulness of this new approach is illustrated by the synthesis of a surfactant having a dimer of isosorbide as hydrophilic group and by the preparation of a structurally unusual bicyclic anhydro carbohydrate.
\end{abstract}

Keywords: isosorbide; glycal; iodoetherification; $\beta$-iodo ethers; radical dehalogenation

\section{Introduction}

In recent years, there has been a growing interest from both academia and industry to develop green materials from renewable resources. Biomass constitutes a pool of natural products which can be used as starting materials. Particularly isosorbide $\mathbf{1}$ is a compound of high importance since it is readily obtained from sorbitol by a double dehydration and is thus a relevant product of the starch industry (Figure 1). Isosorbide $\mathbf{1}$ is highly stable, nontoxic, inexpensive, and commercially available in large quantities. Moreover, it bears two hydroxyl groups that allow further chemical modification. Isosorbide $\mathbf{1}$ is thus an attractive and versatile chemical platform [1]. Isosorbide $\mathbf{1}$ and its less available diastereoisomers isomannide and isoidide have already been investigated as starting materials for the synthesis of chiral promoters in organic synthesis (Figure 1).

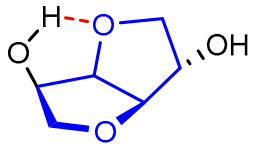

Isosorbide (1)

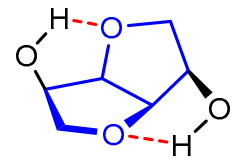

Isomannide

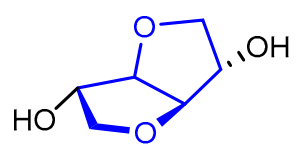

Isoidide

Figure 1. Isosorbide 1 and its diastereoisomers. 
They have been used for the preparation of chiral ionic liquids [2-5], asymmetric phase-transfer catalysts [6], and ligands [7]. Isosorbide 1 and its derivatives have also been employed in medicine as vasodilators [8-10] and used for the synthesis of biodegradable polymers [11], plasticizers, solvents [12-17], and surfactants [18,19]. More recently, our group has been examining the use of isosorbide as starting material for the synthesis of novel amphiphilic compounds (Figure 2) [16-19]. The hydrophilicity of $\mathbf{1}$ has been evaluated and reveals that a single isosorbide moiety holds a fairly limited polarity and is not hydrophilic enough to balance the hydrophobicity of an alkyl chain longer than six carbons. Consequently, isosorbide has been rather used as a hydrophilic linker for the design of surfactants by being inserted between the lipophilic alkyl chain and the polar head $[18,19]$.

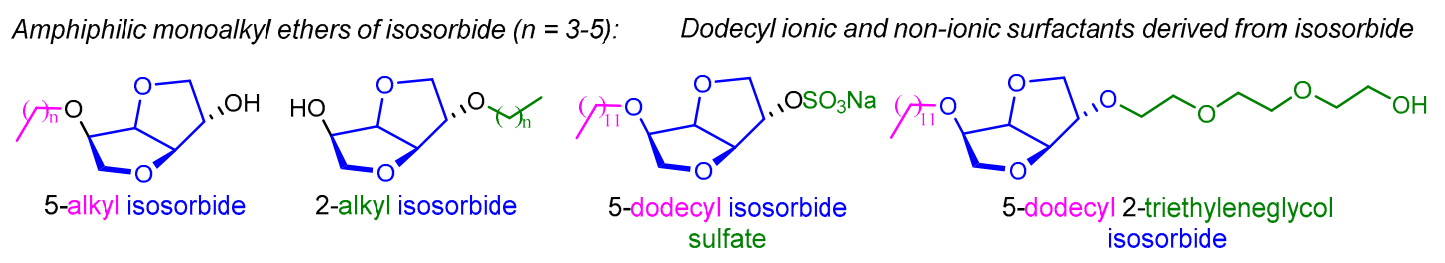

Figure 2. A variety of amphiphilic species derived from isosorbide.

The synthesis and the amphiphilic properties of different agro-based surfactants bearing the isosorbide moiety have been recently reported: (i) anionic surfactants with isosorbide inserted between a dodecyl alkyl chain and a sulfate group [18]; (ii) non-ionic surfactants with isosorbide acting as a rigid hydrophilic linker bearing an aliphatic chain on one hydroxyl and various hydrophilic heads on the other one (Figure 2) [19]. To design a variety of amphiphilic species based on the isosorbide moiety, it would thus be of interest to have in hand a versatile and efficient synthetic pathway to derivatize the free alcohol function, in particular, the addition of hydrophilic bio-based scaffolds, among which isosorbide should be investigated.

In this context, we focused our interest on the use of the haloetherification reaction pioneered by Lemieux [20,21] and Thiem [22,23] for the haloalkoxylation of cyclic enol derived from sugar (glycal) and then for derivatives functionalization. Notably, the use of acetic acid as nucleophile affords the acetoxy intermediate [24]. This approach seems to be versatile and compatible with a wide range of functional groups and would provide a rapid access to a new class of molecules. In order to improve the amphiphilic properties of agro-based surfactants derived from isosorbide, we would like to report in the present paper the synthesis of $\beta$-iodo ethers by iodoetherification of isosorbide-derived glycals with oxygenated nucleophiles in the presence of $N$-iodosuccinimide (NIS). In addition, we have demonstrated the utility of these products by their transformation into valuable organic frameworks.

\section{Results and Discussion}

\subsection{Retrosynthetic Analysis}

We envisioned access to the $\beta$-iodo ethers 3 starting from a glycal intermediate (enol ether) 4 and various oxygenated nucleophiles. The glycal could be obtained from isosorbide $\mathbf{1}$ (Scheme 1).

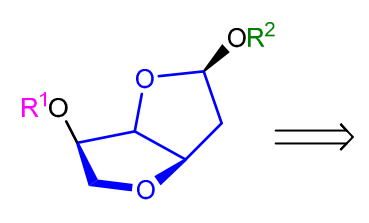

2

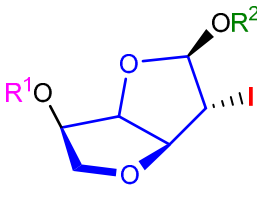

3
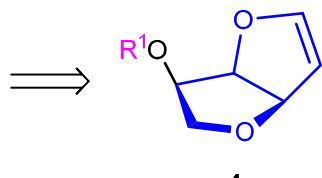

4

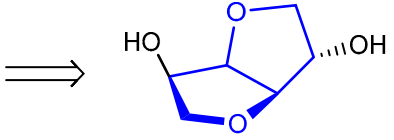

isosorbide (1)

Scheme 1. Retrosynthetic analysis.

The conversion of isosorbide 1 to valuable derivatives by functionalization and/or substitution of the hydroxyl groups is quite difficult because of the different configurations of the C-2 and C-5 positions, resulting in different reactivity and steric hindrance of both hydroxyl groups. Isosorbide 1 
is an asymmetric V-shaped diol consisting of two fused tetrahydrofuran rings having the cis-arrangement at the ring junction (Figure 1). Therefore, the compound bears two sterically and electronically nonequivalent hydroxyl groups at C-2 and C-5 respectively in exo- and endo- orientation with respect to the V-shape molecule. The first one is more accessible whereas the second one is involved in an intramolecular hydrogen bond with the oxygen atom on the neighboring tetrahydrofuran ring [25].

In order to carry out our approach, two different protecting groups, i.e., benzyl and acetyl, were selected to protect the hydroxyl at C-5 regioselectively. The C-5 monobenzyl ether 5 a was synthesized by direct selective benzylation of isosorbide $\mathbf{1}$ using benzyl chloride in presence of a mixture of lithium hydride and lithium chloride in DMSO (Scheme 2) [26]. In the same way, isosorbide 1 can be regioselectively monoacetylated at the endo position using acetic anhydride in the presence of catalytic amount of lead(II) oxide to afford $\mathbf{5 b}$ in high yield [27]. Conversion to the corresponding glycals $4 \mathbf{a}[7,28]$ and $\mathbf{4 b}[3,4]$ was achieved by a two-step process: preliminary conversion to their triflate derivatives followed by in situ elimination of the triflate moiety with 1,8diazabicyclo[5.4.0]undec-7-ene (DBU) [29]. It is noteworthy to mention that glycals $\mathbf{4 a , b}$ are stable under neutral conditions and could be purified by flash chromatography. Moreover, they could be stored in a freezer $\left(-18^{\circ} \mathrm{C}\right)$ under argon for weeks without noticeable decomposition. However acidic conditions promote a rearrangement that leads to the corresponding mono protected 2-furanylethanediol [30,31].

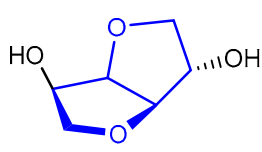

1

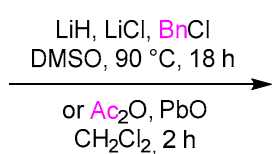

$\mathrm{CH}_{2} \mathrm{Cl}_{2}, 2 \mathrm{~h}$

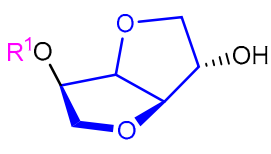

5a $\mathrm{R}^{1}=\mathrm{Bn}(33 \%)$

5b $R^{1}=A c(92 \%)$

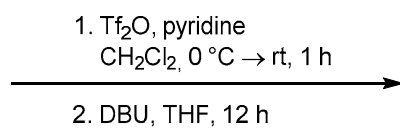

2. DBU, THF, $12 \mathrm{~h}$

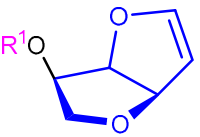

4a $\mathrm{R}^{1}=\mathrm{Bn}(99 \%)$

4b $\mathrm{R}^{1}=\mathrm{Ac}(76 \%)$

Scheme 2. Synthesis of glycals $\mathbf{4 a , b}$.

\subsection{Iodoetherification of Glycals}

Further haloetherification of glycals $\mathbf{4 a}$ and $\mathbf{4 b}$ with various oxygenated nucleophiles were investigated. As a model reaction, 4a was first treated with NIS and methanol $7 \mathbf{a}$ in $\mathrm{CH}_{2} \mathrm{Cl}_{2}$ [32]. After reaction completion, only one diastereoisomer was detected from the crude mixture by ${ }^{1} \mathrm{H}$ NMR. Purification by flash chromatography gave the $\beta$-iodo ether 3aa in 78\% yield (Scheme 3 and Figure 3).

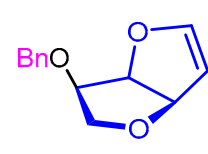

$4 a$

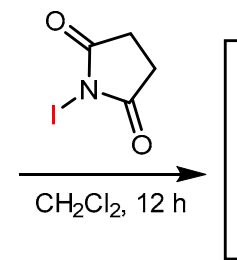

Scheme 3. NIS-mediated asymmetric iodoalkoxylation of glycal 4 a.

To test the versatility of this methodology, a variety of alcohols was then screened. Primary alcohols such as decanol $\mathbf{7 b}$, (S)-glycidol $\mathbf{7 c}$, and $(S)-(+)-1,2$-isopropylideneglycerol $\mathbf{7 d}$ gave the corresponding products $3 \mathbf{a b}-\mathbf{a d}$ in good yields. Diols such as ethylene glycols $7 \mathbf{e}, \mathbf{f}$ and 1,3propanediol $7 \mathrm{~g}$ led to the $\beta$-iodo ethers 3ae-ag in moderate to good yields. In these examples, one can notice that no product from the addition of both hydroxyl groups to two glycal moieties could be isolated. Only the compounds bearing the free hydroxyl group at the end chain have been obtained. Sterically hindered alcohols $7 \mathrm{~h}-\mathrm{m}$ also gave haloetherification products in the presence of NIS without a loss of reactivity, except for tert-butanol $\mathbf{7 m}$. In the case of isosorbide derivatives $7 \mathbf{k}$ and $\mathbf{7 l}$ acting as nucleophiles, dimers 3ak and 3al have been obtained in good yields. Benzyl alcohol $\mathbf{7 n}$ 
reacted smoothly with glycal 4 a to afford compound 3an bearing two similar protecting groups in high yield (88\%), whereas phenol 70 led to the phenoxy product 3ao in only $54 \%$.

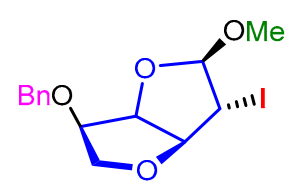

3aa (78\%)<smiles>CCO[C@@H]1OC2C(O)CO[C@@H]2[C@H]1I</smiles>

$3 a b(80 \%)$
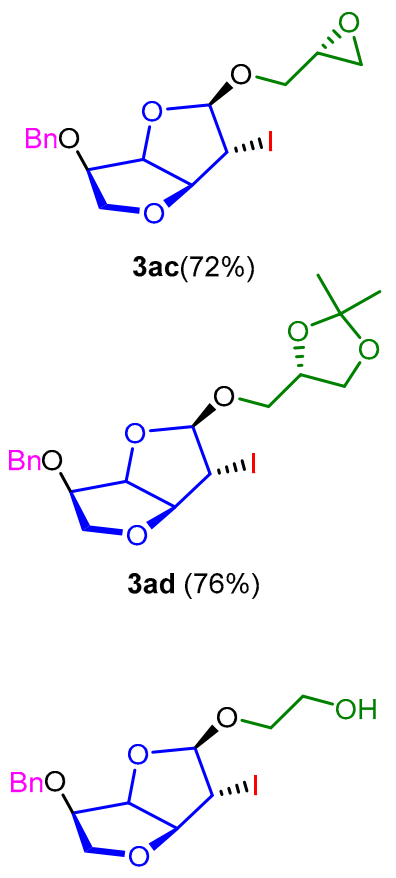

3ae $(80 \%)$

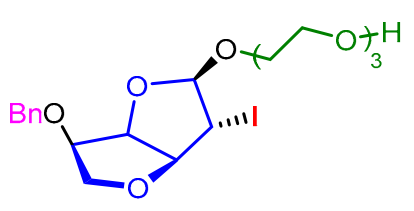

3af $(86 \%)$

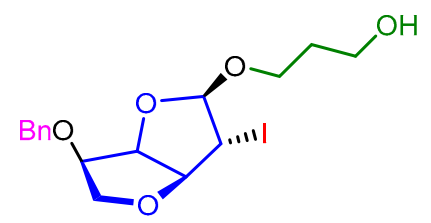

$3 \operatorname{ag}(57 \%)$

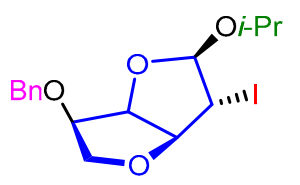

3ah (92\%)

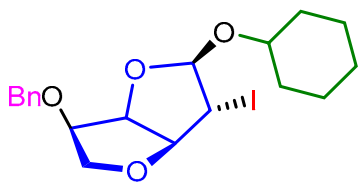

3ai (71\%)

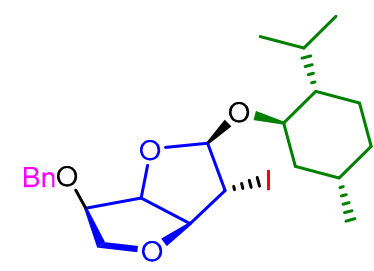

3aj (71\%)

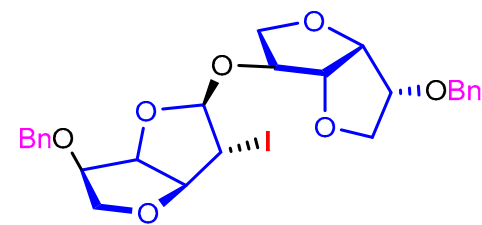

3ak $(60 \%)$

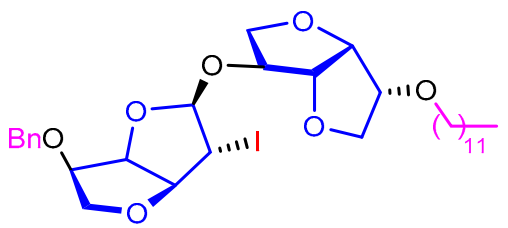

3al $(66 \%)$

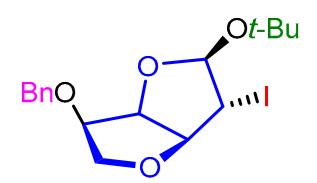

3 am (59\%)

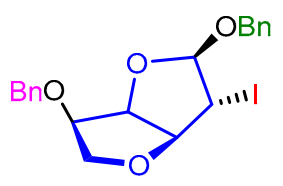

3an (88\%)

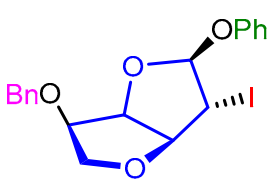

3 ao $(54 \%)$

Figure 3. Compounds 3a prepared.
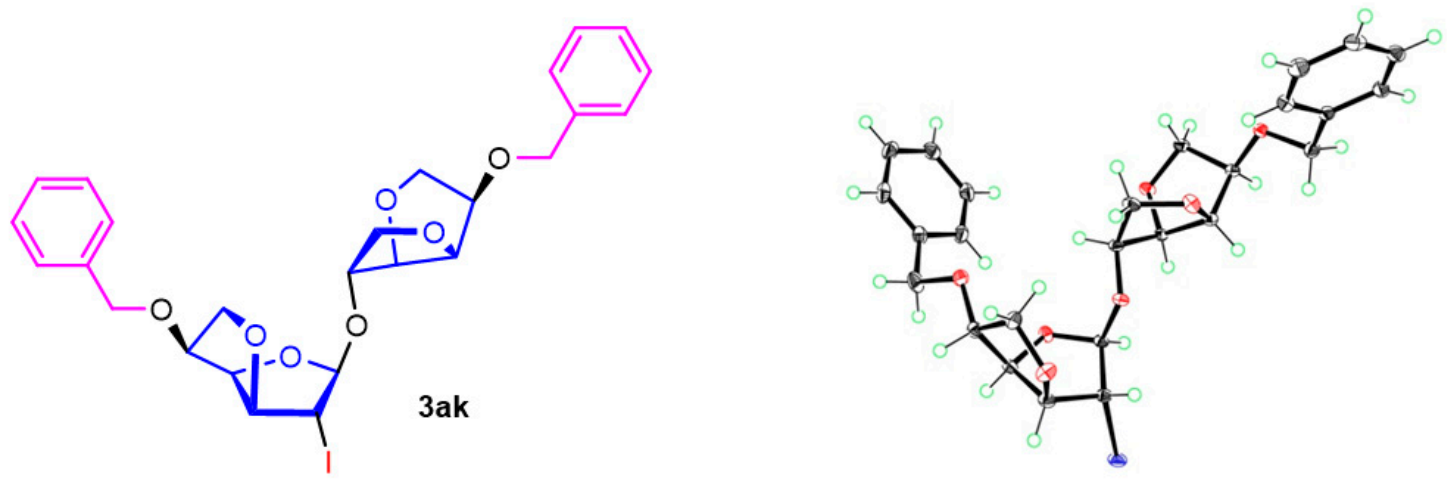

Figure 4. ORTEP plot of $\beta$-iodo ether 3ak. 
The relative stereochemistry was determined by X-ray analysis on compound 3ak and revealed a trans selectivity (Figure 4). The regioselectivity and the stereospecificity of the NIS-mediated addition of alcohol $7 \mathbf{k}$ to glycal $\mathbf{4 a}$ could be explained by the $\mathrm{V}$-shape of the isosorbide derivative. Attack by NIS occurs on the sterically more favored $\beta$-face of the glycal whereas the approach of the reagent to the $\beta$-face is unfavored due to the steric hindrance (Scheme 3 ). The resulting iodonium ion 6a is then attacked from the $\beta$-face by the alcohol to give 3ak as the main product [33].

Iodoetherification of glycal $\mathbf{4} \mathbf{b}$ was achieved in the same reaction conditions and $\beta$-iodo ethers 3ba, 3be, 3bh, 3bk, 3bl, and 3bn were obtained in high yields and selectivity (Scheme 4 and Figure 5).

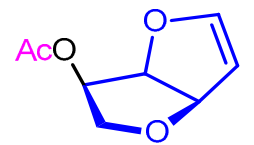

$4 b$

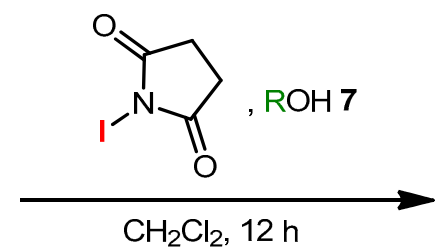

$\mathrm{CH}_{2} \mathrm{Cl}_{2}, 12 \mathrm{~h}$

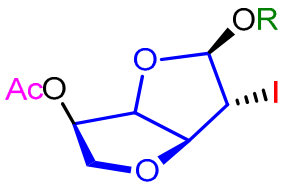

3b

Scheme 4. NIS mediated asymmetric iodoalkoxylation of glycal $4 \mathbf{b}$.

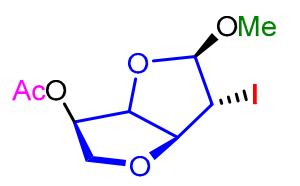

3ba (85\%)<smiles>CC(=O)OC1CO[C@@H]2C1OC(OC1COC3C1OC[C@H]3O)[C@H]2I</smiles>

3bk $(85 \%)$
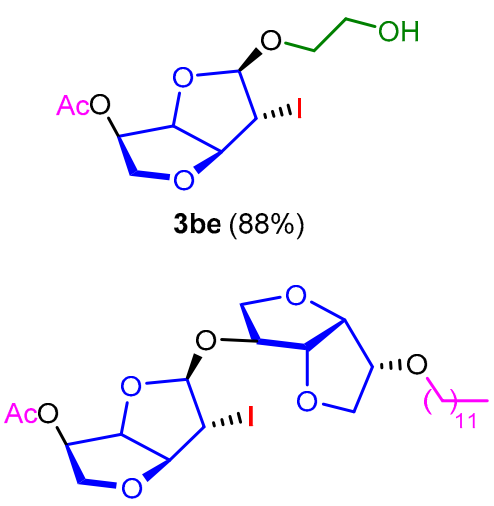

3 bl $(82 \%)$

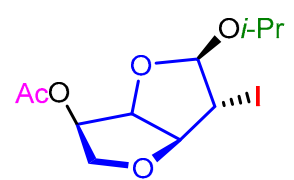

3bh $(93 \%)$

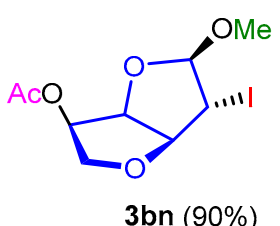

Figure 5. Compounds $3 \mathbf{b}$ prepared.

\subsection{Radical Dehalogenation}

With these new derivatives 3 in hand, their potential further transformations were next investigated. Iodide is an interesting element for functionalization but it could also be easily removed. Tris(trimethylsilyl)silane (TTMSS) is the most well-known alternative to tin hydride as a radicalbased reducing agent for functional group modifications [34]. Radical deiodination of a structurally differentiated $\beta$-iodo ethers 3 was performed by TTMSS using azobisisobutyronitrile (AIBN) as initiator (Scheme 5). In all examples iodide was cleanly removed to afford the deiodinated compounds 2aa, 2ak, 2al, 2an, 2ba, 2bh, 2bk, 2bl, and 2bn in high yields (83-99\%) (Figure 6).

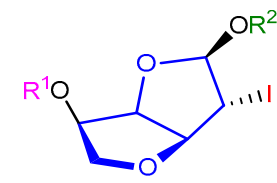

3

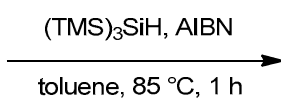

toluene, $85^{\circ} \mathrm{C}, 1 \mathrm{~h}$

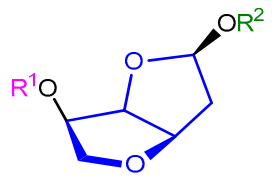

2

Scheme 5. Radical dehalogenation of 3. 


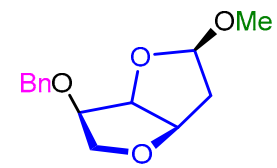

2aa (91\%)<smiles>BrOC1COC2CC(C(Br)Cc3ccccc3)C1O2</smiles>

2an (83\%)

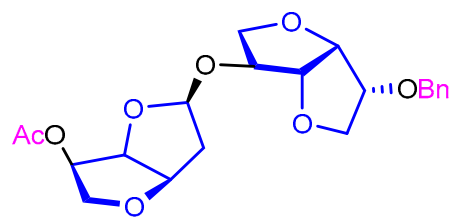

2bk (97\%)

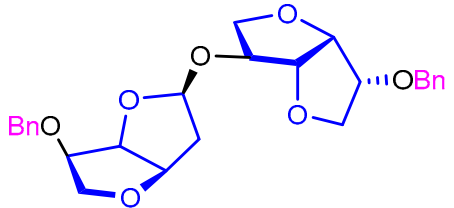

2ak (97\%)

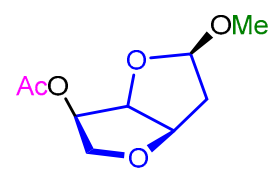

2ba (99\%)<smiles>CC(=O)O[C@H]1CO[C@@H]2CC(OC3COC4C3OC[C@@H]4O[AlH2])OC12</smiles>

2bl (98\%)

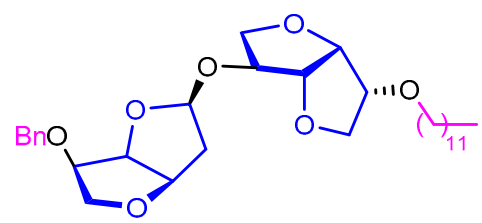

2al (97\%)<smiles>CCCOC1C[C@@H]2OCC(OC(C)=O)C2O1</smiles>

2bh $(90 \%)$

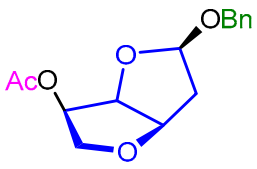

2bn (86\%)

Figure 6. Compounds 2 prepared.

Finally, we were interested in the use of bibenzylated compound 2an which was obtained in two steps (73\% overall yield) from glycal $\mathbf{4 a}$ and appears as an excellent precursor to Saurospunol 8 (Scheme 6). Maytansinoids are a family of 19-membered macrocyclic lactams having extraordinary cytotoxic and antineoplastic activities and they are the products of the bacterium Actinosynnema pretiosum ssp. auranticum ATCC 31565 [35,36]. Recently, a couple of unusual carbohydrates have been isolated from the carbohydrate portion of the solid-state fermentation extract of this bacterium and their structures have been assigned by NMR spectroscopy. Among them, the presence of Saurospunol 8 has been reported [37,38]. Hydrogenolysis of 2 an was successfully achieved in similar conditions described above to afford the unusual carbohydrate Saurospunol 8 as a mixture of anomers (Scheme 6). The spectroscopic data are in agreement with the literature [39].

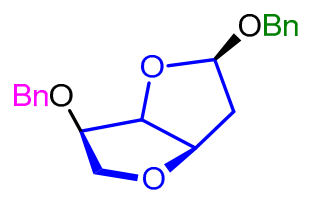

2an

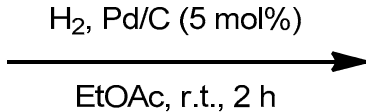

EtOAc, r.t., 2 h

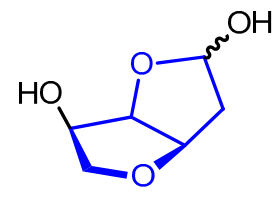

8

Scheme 6. Hydrogenolysis and access to Saurospunol 8.

\subsection{Deprotection}

We pursued investigations by removing the protecting groups to emphasize the utility of this approach. During the synthesis of glycals $\mathbf{4} \mathbf{a}, \mathbf{b}$, two different protecting groups were selected (Scheme 2). Deprotection is exemplified on compounds 2al and $\mathbf{2 b l}$. Benzyl was cleanly cleaved by hydrogenolysis in the presence of catalytic amount of palladium whereas the acetyl group was easily hydrolyzed under mildly basic conditions to afford amphiphilic dimer 9 derived from isosorbide (Scheme 7). In the aim to access to new agro-based surfactants, dimer 9 is a relevant example. Moreover, the free hydroxyl group is suitable for further functionalization. 


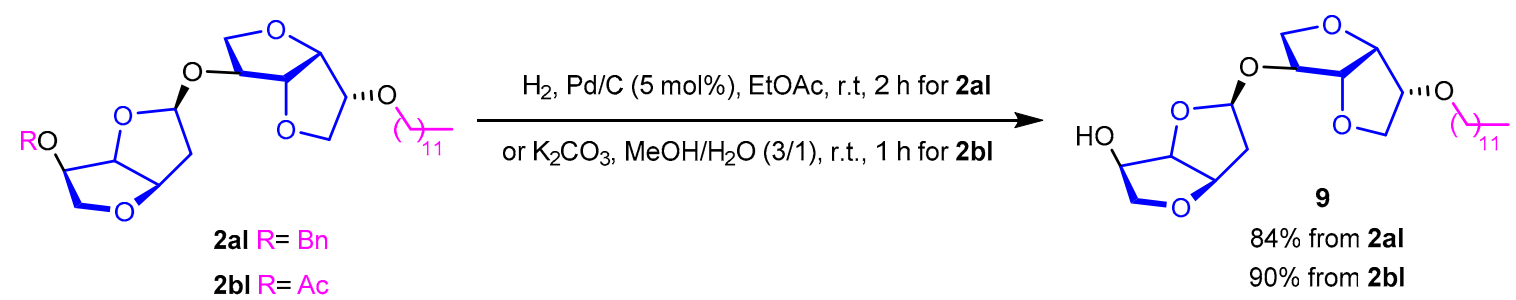

Scheme 7. Deprotection of compounds 2al, $2 \mathbf{b l}$.

\section{Conclusions}

In conclusion, an efficient approach has been developed for the iodoetherification of isosorbidederived glycals. Iodide could be easily removed by radical dehalogenation and the generality of this approach provided a useful access to various derivatives of interest of this bio-sourced synthon. Further applications of this approach for the generation of suitably functionalized key scaffolds are in progress and the results of these investigations will be reported in due course.

Acknowledgments: The authors would like to thank first the Fonds Européen de Développement Régional (FEDER), CNRS, Région Nord Pas-de-Calais, and Ministère de l'Education Nationale de l'Enseignement Supérieur et de la Recherche for funding of X-ray diffractometers, and secondly, Marc Bria, CCM, RMN, Université Lille.

\section{References}

1. Rose, M.; Palkovits, R. Isosorbide as a renewable platform chemical for versatile applications-Quo vadis? ChemSusChem 2012, 5, 167-176.

2. Kumar, V.; Olsen, C.E.; Schäffer, S.J.; Parmar, V.S.; Malhotra, S.V. Synthesis and applications of novel bis (ammonium) chiral ionic liquids derived from isomannide. Org. Lett. 2007, 9, 3905-3908.

3. Van Buu, O.N.; Aupoix, A.; Vo-Thanh, G. Synthesis of novel chiral imidazolium-based ionic liquids derived from isosorbide and their applications in asymmetric aza Diels-Alder reaction. Tetrahedron 2009, 65, 22602265.

4. Buu, O.N.; Aupoix, A.; Hong, N.D.T.; Vo-Thanh, G. Chiral ionic liquids derived from isosorbide: synthesis, properties and applications in asymmetric synthesis. New J. Chem. 2009, 33, 2060-2072.

5. Truong, T.K.T.; Nguyen Van Buu, O.; Aupoix, A.; Pegot, B.; Vo-Thanh, G. Chiral Ionic Liquids Derived from (-)-Ephedrine and Carbohydrates: Synthesis, Properties and Applications to Asymmetric Synthesis and Catalysis. Curr. Org. Synth. 2012, 9, 53-64.

6. Kumar, S.; Ramachandran, U. The synthesis and applications of asymmetric phase-transfer catalysts derived from isomannide and isosorbide. Tetrahedron 2005, 61, 4141-4148.

7. Ibrahim, H.; Bournaud, C.; Guillot, R.; Toffano, M.; Vo-Thanh, G. Synthesis of novel chiral monophosphine ligands derived from isomannide and isosorbide. Application to enantioselective hydrogenation of olefins. Tetrahedron Lett. 2012, 53, 4900-4902.

8. Seemayer, R.; Bar, N.; Schneider, M.P. Enzymatic preparation of isomerically pure 1,4:3,6-dianhydro-Dglucitol monoacetates-precursors for isoglucitol 2-and 5-mononitrates. Tetrahedron Asymmetry 1992, 3, $1123-1126$.

9. Ravikumar, K.S.; Chandrasekaran, S. Highly chemoselective reduction of 2, 5-dinitro-1, 4: 3, 6-dianhydroD-glucitol with titanium (III) tetrahydroborates: efficient synthesis of isomerically pure 2-and 5-nitro-1, 4: 3, 6-dianhydro-D-glucitols. Synthesis 1994, 10, 1032-1034.

10. Thatcher, G.R. An introduction to NO-related therapeutic agents. Curr. Top. Med. Chem. 2005, 5, 597-601.

11. Fenouillot, F.; Rousseau, A.; Colomines, G.; Saint-Loup, R.; Pascault, J.P. Polymers from renewable 1, 4: 3, 6-dianhydrohexitols (isosorbide, isomannide and isoidide): A review. Prog. Polym. Sci. 2010, 35, 578-622.

12. Rossi, P.; Wiechers, J.W.; Kelly, C. Improved delivery and efficacy with dimethyl isosorbide. Cosmet. Toiletries 2005, 120, 107-111.

13. Durand, M.; Zhu, Y.; Molinier, V.; Féron, T.; Aubry, J.M. Solubilizing and Hydrotropic Properties of Isosorbide Monoalkyl-and Dimethyl-Ethers. J. Surfactants Deterg. 2009, 12, 371-378.

14. Durand, M.; Mouret, A.; Molinier, V.; Féron, T.; Aubry, J.M. Bitumen fluxing properties of a new class of sustainable solvents: The isosorbide di-alkyl ethers. Fuel 2010, 89, 2729-2734. 
15. Durand, M.; Molinier, V.; Féron, T.; Aubry, J.M. Isosorbide mono-and di-alkyl ethers, a new class of sustainable coalescents for water-borne paints. Prog. Org. Coat. 2010, 69, 344-351.

16. Zhu, Y.; Durand, M.; Molinier, V.; Aubry, J.M. Isosorbide as a novel polar head derived from renewable resources. Application to the design of short-chain amphiphiles with hydrotropic properties. Green Chem. 2008, 10, 532-540.

17. Zhu, Y.; Molinier, V.; Durand, M.; Lavergne, A.; Aubry, J.M. Amphiphilic properties of hydrotropes derived from isosorbide: Endo/exo isomeric effects and temperature dependence. Langmuir 2009, 25, 1341913425.

18. Lavergne, A.; Zhu, Y.; Pizzino, A.; Molinier, V.; Aubry, J.M. Synthesis and foaming properties of new anionic surfactants based on a renewable building block: Sodium dodecyl isosorbide sulfates. J. Colloid Interface Sci. 2011, 360, 645-653.

19. Lavergne, A.; Zhu, Y.; Molinier, V.; Aubry, J.M. Aqueous phase behavior of isosorbide-based non-ionic surfactants. Colloids Surf. A Physicochem. Eng. Asp. 2012, 404, 56-62.

20. Lemieux, R.U.; Fraser-Reid, B. The bromination and halogenomethoxylation of D-glucal triacetate. Can. J. Chem. 1964, 42, 532-538.

21. Lemieux, R.U.; Morgan, A.R. The synthesis of $\beta$-d-glucopyranosyl 2-deoxy- $\alpha$-d-arabino-hexopyranoside. Can. J. Chem. 1965, 43, 2190-2198.

22. Thiem, J.; Karl, H.; Schwentner, J. Synthese $\alpha$-verknüpfter 2'-Deoxy-2'-iododisaccharide. Synthesis 1978, 696-697.

23. Thiem, J.; Ossowski, P. Studies of hexuronic acid ester glycals and the synthesis of 2-deoxy- $\beta$-glycoside precursors. J. Carbohydr. Chem. 1984, 3, 287-313.

24. Kim, C.U.; Misco, P.F. Facile, highly stereoselective synthesis of 2',3'-dideoxy-and 2',3'-didehydro-2',3t'dideoxy nucleosides via a furanoid glycal intermediate. Tetrahedron Lett. 1992, 33, 5733-5736.

25. Claffey, D.J.; Casey, M.F.; Finan, P.A. Glycosylation of 1, 4: 3, 6-dianhydro-d-glucitol (isosorbide). Carbohydr. Res. 2004, 339, 2433-2440.

26. Abenhaim, D.; Loupy, A.; Munnier, L.; Tamion, R.; Marsais, F.; Queguiner, G. Selective alkylations of 1,4:3,6-dianhydro-d-glucitol (isosorbide). Carbohydr. Res. 1994, 261, 255-266.

27. Stoss, P.; Merrath, P.; Schlüter, G. Regioselektive Acylierung von 1,4:3,6-Dianhydro-D-glucit. Synthesis 1987 174-176.

28. Huynh, K.D.; Ibrahim, H.; Toffano, M.; Vo-Thanh, G. New class of chiral ligands derived from isosorbide: first application in asymmetric transfer hydrogenation. Tetrahedron Asymmetry 2010, 21, 1542-1548.

29. Dillon, G.P.; Gaynor, J.M.; Khan, D.; Carolan, C.G.; Ryder, S.A.; Marquez, J.F.; Reidy, S.; Gilmer, J.F. Isosorbide-based cholinesterase inhibitors; replacement of 5-ester groups leading to increased stability. Bioorg. Med. Chem. 2010, 18, 1045-1053.

30. Paolucci, C.; Rosini, G. Approach to a better understanding and modeling of (S)-dihydrofuran-2-yl,(S)tetrahydrofuran-2-yl-, and furan-2-yl- $\beta$-dialkylaminoethanol ligands for enantioselective alkylation. Tetrahedron Asymmetry 2007, 18, 2923-2946.

31. Berard, D.; Giroux, M.A.; Racicot, L.; Sabot, C.; Canesi, S. Intriguing formal [2+3] cycloaddition promoted by a hypervalent iodine reagent. Tetrahedron 2008, 64, 7537-7544.

32. Chao, Q.; Zhang, J.; Pickering, L.; Jahnke, T.S.; Nair, V. Concise and stereospecific synthesis of novel bicyclic dideoxynucleosides as potential antiviral agents. Tetrahedron 1998, 54, 3113-3124.

33. Bravo, F.; Viso, A.; Alcázar, E.; Molas, P.; Bos, C.; Castillón, S. Computational Insight into the Reaction Intermediates in the Glycosylation Reaction Assisted by Donor Heteroatoms. J. Org. Chem. 2003, 68, 686691.

34. Chatgilialoglu, C.; Lalevée, J. Recent applications of the (TMS) 3SiH radical-based reagent. Molecules 2012, 17, 527-555.

35. Higashide, E.; Asai, M.; Ootsu, K.; Tanida, S.; Kozai, Y.; Hasegawa, T.; Kishi, T.; Sugino, Y.; Yoneda, M. Ansamitocin, a group of novel maytansinoid antibiotics with antitumour properties from Nocardia. Nature 1977, 270, 721-722.

36. Asai, M.; Mizuta, E.; Izawa, M.; Haibara, K.; Kishi, T. Isolation, chemical characterization and structure of ansamitocin, a new antitumor ansamycin antibiotic. Tetrahedron 1979 35, 1079-1085.

37. Serrano, J.A.; Román, E. A Convenient Synthesis of 3, 6-Anhydro-2-deoxy-D-glucose [Isoglucal] and Some of Its Derivatives. J. Carbohydr. Chem. 1993, 12, 237-246. 
38. Lu, C.; Bai, L.; Shen, Y. Five unusual natural carbohydrates from Actinosynnema pretiosum. Chem. Nat. Comp. 2008, 44, 594-597.

39. Markovič, M.; Koóš, P.; Gracza, T. A Short Asymmetric Synthesis of Sauropunols A-D. Synthesis 2017, 49, 2939-2942.

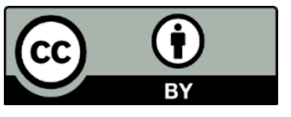

(C) 2019 by the authors. Licensee MDPI, Basel, Switzerland. This article is an open access article distributed under the terms and conditions of the Creative Commons Attribution (CC BY) license (http://creativecommons.org/licenses/by/4.0/). 